CUPAUAM. 18-1992, 399-419

\title{
INSCRIPCIONES DEL NORTE Y SUROESTE DE LA PROVINCIA DE CACERES: REVISION Y NUEVAS APORTACIONES. II
}

\author{
J. L. Gamallo \\ H. GIMENO \\ G. VARGAS \\ Consejo TÉCNiCo de Hispania EPIGraphica
}

\section{Resumen}

En el presente trabajo se revisan y se dan a conocer varias inscripciones procedentes de algunas localidades de las zonas Norte y Suroeste de la provincia de Cáceres. Entre ellas, tres de Augustobriga que, aunque ya conocidas, se encontraban en paradero desconocido o de las que no se tenía reproducción gráfica.

\section{Summary}

This paper offers the texts and photographs of some inscriptions from Northern and Southwestern areas of the province of Cáceres, in the ancient Lusitania. Three of them had been found in Augustobriga (modern Talavera la Vieja), but they were lost until now.

\section{HERGUIJUELA}

1. Estela rectangular de granito local cortada por el lado izquierdo y superior y por detrás, de forma que actualmente presenta una sección trapezoidal. En el borde superior conserva la parte inferior de un doble círculo y una escuadra en la esquina derecha. Se conserva en el domicilio de D. Antonio Nufrio, Travesía de Zorita, $n^{\circ} 7$, quien la trajo de una casa situada en la calle del Canchillo (antigua calle del Llanillo) donde sirve de banco. Medidas: 52 × 31 x 17-16,5. Letras: 7, capital cuadrada de buena factura. Interpunción: punto. (Lám. I, fig. 1).

$[D($ is $)] \cdot M($ anibus $) \cdot s($ acrum $)$.

[..]niae $\cdot \mathrm{Ma}$ -

[.. li]b(ertae). Veneriâe

$[$ an $($ norum $) \cdot] X L \cdot h($ ic $) \cdot s($ ita $) \cdot e(s t) \cdot s($ it $) \cdot t($ ibi $)$

$5[$ t(erra) $\cdot l($ evis $) \cdot]$ frât $\langle e>r \cdot f($ ecit $)$ 
Como al principio de las líneas 4 y 5 es segura la restitución de dos letras, en 1.2 habría un gentilicio al que le faltarían sólo una o dos letras quizá Mania.

El nombre del patrono podría ser Manius, también atestiguado en Coria (CPILC 771). En femenino aparece en Oropesa (TO) ( $C I L$ II 945), aunque en este caso estaría invertido el orden normal de nomen + cognomen pues se trata de una Severa Mania L. $f$. El cognomen Veneria aparece en Cáceres ( CIL II 722). Por el formulario se fecharía en el siglo II.

\section{PERALES DEL PUERTO (1)}

2. Ara de granito local, con coronamiento formado por tres molduras que corren por la cuatro caras. La parte superior está muy erosionada. Fue hallada formando parte de la pared de una finca en la Dehesa de Arriba (2). Actualmente se conserva en un domicilio particular de Acebo. Medidas: 37 × 57 × 20. Letras: 4; capital cuadrada algo rústica. Interpunción: punto. (Lám I, fig. 2)

$$
\begin{aligned}
& \text { IONI } \\
& \text { OR } \cdot M A \\
& \text { ACANI. } \\
& \text { ARCOBRI } \\
5 & \text { GENSES } \\
& {[A] \cdot P \cdot A \cdot L }
\end{aligned}
$$

El texto ha sido retocado recientemente en Il. 1, 2 y 3. Sin embargo las líneas 1 y 2 son evidentes: presentan una dedicación a Iuppiter Optimus Maximus. La l. 3 es más problemática puesto que en función del texto que sigue, Arcobrigenses, lo lógico sería pensar en unos vicani, aunque, no vemos en la pieza ningún rastro del primer trazo de la V.

Acani podría interpretarse como un nominativo plural, un grupo étnico, los Acani. No sería la primera vez que aparece una referencia de este tipo relacionada con Arcobriga. En la inscripción rupestre de la Fonte do Idolo en Braga (CIL II 3419), se acepta comúnmente, ya desde Hübner, que el término Ambimogidus designa la división étnica a la que pertenecía Caecilius Fronto de la ciudad de Arcobriga que dedicó el monumento. También podría pensarse en unos $A(u l i)$ Cani, una familia que fuera originaria de Arcobriga, interpretación que resulta muy forzada. Así pues, preferiríamos corregir Acani en ${ }^{-} i{ }^{\prime}$ cani y de este modo desarrollaríamos:

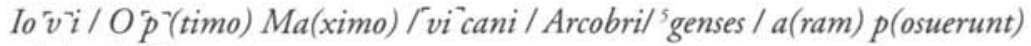
a(nimo) l(ibentes)

(1) Agradecemos a Pilar Urbano y Octavio Sanz, de Acebo habernos comunicado la noticia y facilitado las fotos.

(2) Junto a este ara se encontró otra, de la que hemos tenido noticia se conserva en una colección particular de Badajoz. Según su descubridor, el texto reza IOVI OP /MAX AR/CLASEPE/ALS. Aunque la 1. 4 es la que ofrece algún problema, el texto se podría reconstruir de la siguiente manera: Iovi Op(timo) / Max(imo) Ar / cobrigenses/a(nimo) l(ibentes) p(osuerunt), o algo muy parecido. 
Conocemos con seguridad una localidad con el nombre de Arcobriga en Celtiberia (Tovar 1989, p. 406). La existencia de otra Arcobriga, mencionada por Ptolomeo, que habría estado situada en el Occidente de la Península (Tovar 1989, p. 308) no ha sido confirmada de momento, aunque, si fuera cierta, preferiríamos que estos vicani procedieran de esta última, de la que no sería extraño que procediesen otros Arcobrigenses atestiguados en la zona próxima de Coria (CIL II 765) y Braga (CIL II 2419).

Testimonios de dedicaciones a Júpiter por vicani indígenas en Lusitania, no son excepcionales: vicani Tongobrigenses Brozas, Cáceres CIL II 743 = CPILC 97); vicani Camalocenses (freguesía y concelho Crato, distrito Portalegre CIL II 170); vicani Atucausenses (CIL II 6287, freguesía y concelho Amarante, distrito Porto) y vicani Mace[..] enses (en el mismo Perales del Puerto, $c f$. infra, $\mathrm{n}^{\circ}$ 3). Para Curchin en su estudio sobre vici y pagi en Hispania (3) (Curchin 1985), en estas dedicaciones a Júpiter podría ocultarse una divinidad indígena (Curchin, art. cit., p. 329). La proximidad del lugar del hallazgo de estas dos aras al monte Jálama, situado al Norte de S. Martin de Trevejo, que Albertos (Albertos 1985, p. 469-470) identifica con el dios Salama, divinidad considerada por Melena (Melena 1985, p. 485) como posible versión indígena de Júpiter, avalarían la hipótesis de Curchin.

3. Árula de granito con molduras y focus. Se hallaba muy desgastada en los lados y por arriba debido a que era utilizada como piedra de afilar. La noticia procede de las schedae de L. Albertos, quien la recibió de A. Sánchez Paredes y que nos ha facilitado A.U. Stylow. En el pueblo, donde la hemos buscado, ignoran su paradero actual, por lo que no hemos podido obtener las medidas (Lám. II, fig. 3).

\author{
[Iovi] \\ Optumo \\ Maxum[o] \\ vicân[i] \\ 5 Mace[-c. 1-2-] \\ ense[s] \\ [a]ram \\ [p]osuer- \\ "unt" v(otum) s(olverunt) l(ibentes) [a(nimo)?]
}

Como las dos anteriores, se trata de una dedicación a Júpiter (¿Salama.) por parte de unos vicani de un vicus desconocido, aunque el nombre del mismo procede de la misma raíz indoeuropea que algunos nombres como Macana, Macenus (Albertos 1965 p. 141; Palomar 1957 p. 80)

(3) A su catálogo de inscripciones de vicani en Hispania, además de nuestros nn. 2 y 3 habría que añadir una recientemente hallada cerca de Talarrubias, rota en dos partes, cuyo texto reza según foto publicada en el periódico Extremadura (6-5-1992) Cereri / L . Iulius / L. f. Afer / vicanis / d. d. (HEp. 3,97) La parte superior, Il. 1 y 2 , ya habria sido publicada dos veces por D. Vaquerizo Gil en "Epigrafia romana inédita de la llamada "Siberia Extremeña", Revista de Estudios Extremeños 42, 1, 1986, p. 129-130 (AE 1986, 322; HEp 1,111) y en "Epigrafia romana en Badajoz", Revista de Arqueologia 70, 1987, p. 33, lám. XIII. Recientemente veáse también P. Guichard-S. Lefevbre, "Un nouveau vicus en Hispanie d'après une inscription inédite d'Estrémadure", Mélanges de la casa Veláquez 28 (1), 1992, pp. 165-179, especialmente pp. 176-178 y nota 63 para los vici de Lusitania y la relación de éstos con el culto a Júpiter. 


\section{PLASENZUELA}

4. Ara de granito rosado local a la que le falta su parte inferior, con coronamiento formado por una moldura. Se conserva en un corral propiedad de D. Antonio Toril Avilero contiguo a los terrenos donde apareció al arar (4). Medidas: (41) x 22 × 21. Letras: excepto la O, que mide $5 \mathrm{~cm}$. capital rústica. (Lám. II, fig. 4 y lám. III, fig. 5)

$$
\begin{aligned}
& \text { CAV } \\
& C O E \\
& \text { [.]+ }
\end{aligned}
$$

$\mathrm{La}+$ de 1.3 corresponde a un trazo vertical. Aunque sería posible interpretar Cauco como el dativo de un teónimo, preferiríamos considerarlo como un nominativo de un nombre indígena en -o, de radical Cauc*, frecuente en nombres celtas (Palomar 1957, p. 60). Las reducidas dimensiones del ara unido a la $E$ de 1.2 y el trazo vertical de 1.3 sugieren esta posible lectura:

\section{Cau/co e $(x) /[v($ oto $)] p$ (osuit)}

La ausencia de la mención a la divinidad y el hecho de que apareciera junto con otra ara hacen suponer la existencia de un santuario a una divinidad por el momento desconocida.

\section{ROBLEDILLO DE TRUJILLO}

5. Parte inferior de una estela de granito rojo con un cuadrado rehundido debajo del texto, seguramente por una reutilización posterior. Se encuentra sirviendo de jamba en la puerta de una cerca en una zona de la finca El Alijar o Los Alijares. Medidas: (50) x 35 x 21. Letras: 4,5-4, capital cuadrada irregular. Interpunción: punto. (Lám. IV, fig. 7)

$$
\begin{aligned}
& {[--s(\text { it })]} \\
& t(\text { ibi }) \cdot t(\text { erra }) \cdot l(\text { evis }) \\
& f(\text { ilii }) \cdot f(\text { aciendum }) \cdot c \cdot c \text { (uraverunt }) .
\end{aligned}
$$

En 1.3 conviene destacar el empleo de doble $\mathrm{C}$ para indicar el plural del verbo final

6. Parte inferior de un bloque de granito rojo pulimentado, empotrado en la jamba derecha de la puerta de una cerca en la finca El Alijar o Los Alijares (5). En la parte inferior izquierda presenta una escuadra, y restos de otra en la derecha. Medidas: (45) x 34 x ?. Letras: 7-6, capital cuadrada irregular. Interpunción: punto. (Lám. IV, fig. 8)

(4) Junto con este ara apareció otra (Lám. III, fig. 6) que se conserva en el mismo corral sirviendo de solera a la puerta de una cerca con la inscripción en la parte no visible. Se trata de un ara con coronamiento y basa moldurados y fuste liso. Medidas aprox.: $55 \times 26 \times 34$. 
$+\hat{a n}($ norum $) \cdot L V$.

$h($ ic $) \cdot s(--) \cdot s($ it $) \cdot t($ ibi $) \cdot t($ erra $) \cdot l($ evis $)$

HEp 3, 132

\section{RUANES}

7. Parte inferior de una estela rectangular de granito local empotrada en la pared de una casa en la calle $\mathrm{D}^{\mathrm{a}}$ Manuela Avila $\mathrm{n}^{\circ}$ 11, colocada en posición horizontal. Medidas: (61) x 40 x ?. Letras: 10-7, capital cuadrada de buena factura, conservan restos de minio. Interpunción: triángulo (Lám. VI, fig. 12).

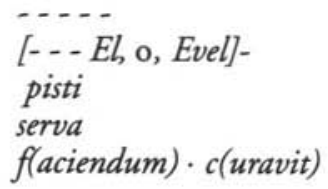

$A \sin$ travesaño.

Se trata de la parte final de un epitafio funerario en el que se menciona a una esclava, la dedicante, cuyo nombre desconocemos. [- - - ]pisti debe ser el genitivo de un cognomen griego, e.g. Elpistus o Evelpistus, por tanto cabría esperar delante, como mínimo, el nomen del patrono. Además faltaría el nombre y la edad del difunto/a.

8. Estela rectangular de granito cortada por arriba, en muy mal estado de conservación. Sirve de pilastra en una casa con arquerías de los siglos XV-XVI actualmente en ruinas, llamada de los Holguín. Medidas: (59) x 30 × 23; letras 6,5 aprox. Lectura de A. Ma Canto, según foto (Lám. VII, fig. 13).

$$
\begin{aligned}
& \text { [B]elici- } \\
& \text { na G(aiae) lib(erta) } \\
& \text { h(ic) s(ita) e(st) } \\
& \mathrm{E}=I I
\end{aligned}
$$

El cognomen Belicina está documentado en el Nórico (CIL III 5225; Kajanto 1965, p. 258). Por el formulario se fecharía en la primera mitad del siglo I.

\section{SALVATIERRA DE SANTIAGO (6)}

9. Nueva propuesta de lectura en 1.1 de esta estela, publicada por vez primera por M. Roso de Luna (Roso de Luna 1905 p. 70) y corregida por A. González Cordero (González Cordero 1985 p. 292-293, nº 6, lám. 5 = HEp 1, 185) (Lám. VI, fig. 11).

(5) En las proximidades se encuentra el ara publicada por Redondo (Redondo 1988, p. 328, n० 3; HEp 3, 135 con ligeras correcciones) de la que ofrecemos las medidas de las letras, 4,5-4, y la foto que no había sido publicada (Lám. V, fig. 9).

(6) En esta misma localidad se conserva la inscripción, CPILC 431, de la cual la lectura correcta en L. 3, es la de Fernández Oxea, Macaldici (Fernández Oxea 1951, p. 192) y no la ofrecida en CPILC (Lám. V, fig. 10). 
Câmira
Alluqu[i]
$[f($ ilia $)] \cdot h($ ic $) \cdot s($ ita $) \cdot e(s t)$.

En 1. 1, CAMILA, González Cordero 1985.

El cognomen Camira está ampliamente atestiguado en Lusitania. Por el formulario se fecharía en la primera mitad del siglo I.

\section{SANTA ANA}

10. Parte inferior de una estela rectangular de granito amarillento local procedente de la finca Los Canchales. Medidas: (88) x 40 x 14,5. Letras: 7, capital cuadrada. Interpunción: punto. Actualmente se encuentra sirviendo de banco, adosado a una pared de la calle San Gonzalo, con una franja de cemento que cubre la parte derecha, uniéndola a la pared. Según nos comunicaron, pronto será trasladada al domicilio particular de D. Rafael Poblador Pacheco (7) (Lám. VII, fig. 14).

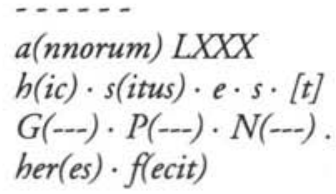

En 1. 2, al final, hay espacio para, como mucho, una letra más. Por ello, a pesar de las interpunciones, preferimos restituir una sola $T$ más que la fórmula s.t.t.l., ni siquiera cabría s.t.l. que es bastante usual en la zona. En l. 3 probablemente los tria nomina del dedicante, el heredero, que se encargó de erigir el monumento al fallecido, de ochenta años, cuyo nombre desconocemos.

\section{TALAVERA LA VIEJA}

11. Bloque paralelepipédico de granito, con el campo epigráfico rehundido y enmarcado por una moldura. Las 1. 4-6 están muy erosionadas. Medidas: 121 x 45,5 x 23,5. Letras: 9-8, capital cuadrada irregular. Interpunción: punto. Hasta el año 1962, en que esta localidad fue cubierta por el pantano de Valdecañas, esta inscripción estuvo en una casa de la calle Real, como señala CIL II 928, que lo toma de Hermosilla y Sandoval (Hermosilla 1796, p. 349, estampa 2, letra H). Actualmente se conserva en el domicilio de D. Modesto Rubio en Bohonal de Ibor. (Lám.. VIII, fig. 16)

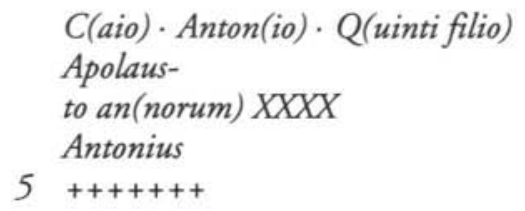

(7) En este mismo domicilio se conserva, sirviendo de jamba a la puerta de entrada, la inscripción de CPILC 444 de la que la lectura correcta es la de Fernández Oxea, (Fernández Oxea 1944-45, p. 90) y no la de Hurtado de San Antonio. (Lám..VIII, fig. 15) 
[-c.4-] f(aciendum) c(urav---)

h(ic) s(itus) e(st) s(it) t(ibi) t(erra) l(evis)

CIL II 928 (CPILC 473)

En 1. 4 ANTOS::: V, CIL; en l. 5 PHIAIXA:::, CIL; en 1.6 TOP::: PC, CIL

Los restos de letras de 1.5 son inidentificables, pero probablemente contengan el cognomen y la filiación del dedicante que parece estar emparentado con el fallecido, pues tiene el mismo gentilicio. En ll. 3-6, A. Ma Canto según foto lee: ... Ito an(norum) LXXX / Antonia [.] / f(ilia) Nistale? / et fili f(aciendum) c(uraverunt).

12. Ara de ¿granito? con coronamiento roto en el lado izquierdo. La transición al fuste se realiza a través de una moldura ancha, en la cual está la primera línea del texto. Debajo de ésta, otras dos, un toro y una escocia. El fuste es liso y en la parte inferior presenta restos de la moldura que lo separa de la basa. Letra capital cuadrada tosca.

La descripción y lectura se ha efectuado gracias a una fotografía (Lám.. IX, fig. 17) de la pieza, que debió hacerse en los años cincuenta y que ha sido amablemente cedida por $\mathrm{D}^{\mathrm{a}}$ Julia Reguera Arroyo, sin que sepamos dónde se conserva actualmente la inscripción. El texto coincide con una de las lecturas de CIL II 927, la de Forner, que Hübner considera interpolada. La otra lectura, la de Hermosilla, cuyo dibujo conservamos (Hermosilla y Sandoval 1796, p. 305, estampa 3, letra L) debe corresponder a una inscripción distinta. Hermosilla la describe de la siguiente forma: "la de la let. L es también mármol muy fino, de pie y medio de alto y poco más de uno de ancho; está fixa en la bodega de la casa del teniente cura y tiene también moldura labrada excelentemente" (Lám. IX, fig. 18). Tanto la descripción como el dibujo que presenta Hermosilla no corresponden al ara de la foto cuyo texto coincide con el de Forner. El dibujo de Hermosilla representa un fragmento inferior de mármol ( $45 \times 30 \mathrm{x}$ ?) sin que podamos determinar a qué tipo de soporte perteneció.

La confusión de los dos textos se produjo a partir de Cornide (Cornide 1796, p. 391) que identificó el texto de Forner con el de Hermosilla, siendo las piezas completamente diferentes. Por tanto bajo CIL II 927 (= CPILC 472) se recogen dos inscripciones distintas. La inscripción que da Forner, según la foto, dice:

\footnotetext{
$[----]$ ?

$\operatorname{Vic}(---) \cdot \underline{\operatorname{sac}(r u m)}$

Lucius

Marci $\cdot[f: ?]$

5 v(otum) $\cdot$ s(olvit)
}

\section{3, MARCIVS, CIL. L. 4, L.A. V.S, CIL.}

En 1. 1, podría haber restos de letras. Por ello, la interpretación de $\operatorname{Vic}(---)$ en 1.2 depende de si hubo o no una primera línea donde pudiera estar el nombre del dios, y en este caso vic(---) sería el epíteto de la divinidad, mientras que si no hubo tal línea habría que seguir la interpretación que ya acepta Hübner, como una dedicación a la Victoria. A. Ma Canto propone leer en los restos aparentes de esa 1. 1: [P]at(ri) Iâno, dios venerado en Gallia y, aunque con escasos testimonios, también en Hispania (Blázquez 1962 p. 140, a cuya relación habría que añadir CPILC 735 de Valencia de Alcántara). 
13. En el domicilio de Madrid de la familia Reguera también se conserva ahora la inscripción CIL II 5346 = CPILC 491 (Lám. X, fig. 19), aparecida en 1887, de la que García y Bellido (García y Bellido 1956-1961, p. 237, lám.. CLXXI) ofreció la imagen por primera vez. Se trata de una placa rectangular de mármol, rota por su lado derecho. La cara anterior y los bordes presentan la superficie pulimentada, mientras que la parte posterior está sólo desbastada. En el borde superior presenta los restos de un hueco cuadrangular, tal vez para colocar la grapa de sujeción. Medidas: 41 x 40 × 6. Letras: 6-5,5; $T$ e $I(1.2)$, 7. Interpunción: triángulo.

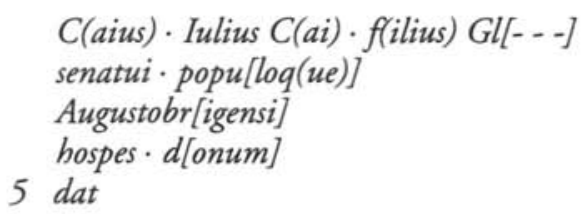

En algunas letras se ha producido un gran desgaste, especialmente en aquellas en que la incisión debió ser muy fina: en 1.1 , en la mitad superior de la $C$ del praenomen; en la $S$ de 1.2 el trazo curvo superior está sin cerrar, la $V$ final sólo conserva el inicio del trazo superior izquierdo; la P de 1.4 ahora no se cierra por arriba; el trazo curvo de las D, en 1.4 y 5 , no está unido al trazo vertical (Lám. X, fig. 20).

\section{APÉNDICE POR JOSÉ V. MADRUGA FLORES}

\section{Inscripciones de Magacela (Badajoz)}

I. Estela de granito con remate semicircular con creciente lunar. Parece ser que fue hallada en el mismo casco urbano al realizar unas obras. Medidas: 131 x 44 x 29. Letras: 7-6,5; capital cuadrada. Interpunción: punto. Se conserva en el pasillo de la planta baja, junto al hueco de las escaleras, del Colegio Público Nuestra Señora de los Remedios. (Lám. XI, fig. 21)

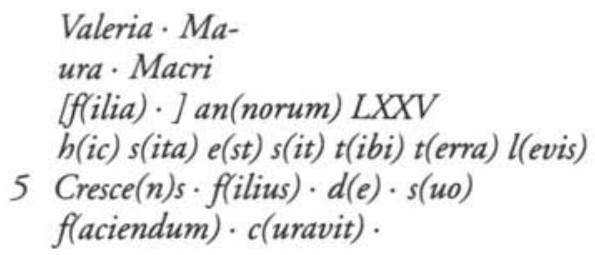

Por el formulario se fecharía en la segunda mitad del siglo I.

II. Fragmento superior de una estela de granito fracturada en las partes derecha e inferior, con remate semicircular con creciente lunar inciso. Fue hallada en 1991 al realizar labores agrícolas en la llamada Huerta de los Remedios, a la izquierda de la ermita del mismo nombre, situada al suroeste de Magacela. Medidas: (52) x 33 x 19. Letras: 6,5-6; capital cuadrada. Interpunción: punto. Se conserva in situ. (Lám. XI, fig. 22). 
Musa [---]

Sabin(ae, i) [ser., lib.?]

an(norum) $\cdot X[---]$

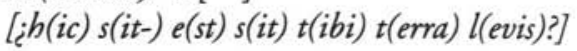

Musa es un cognomen usado tanto por las mujeres como por los hombres, aunque es más habitual que lo lleven las mujeres ( $c f$. Kajanto 1965 p., 216). En l. 1, detrás de Musa quizá un gentilicio del patrono. Por la ausencia de $D$ (is) $M$ (anibus) s(acrum) se fecharía en el siglo I.

\section{Ad. $n^{\circ} 8$}

Recientemente, realizada una nueva autopsia, nos da la impresión de que quizá deba leerse en el sentido inverso, resultando la siguiente lectura:

SIS. F
$+I I C V$
+++
..$-+-+?$

$\mathrm{La}+$ de 1.2 corresponde a dos trazos curvos que se asemejan a una $S$, aunque la panza inferior se cierra demasiado. Las cruces de l. 3 son tres trazos curvos. A pesar de ello, no es posible decidirse por cuál sería la dirección correcta en la que había que leer la pieza, dados su mal estado de conservación y las malas condiciones de visibilidad del lugar donde se encuentra. 


\section{BIBLIOGRAFIA}

AlberTOS, M. L.,1965: La onomástica personal primitiva de Hispania Tarraconense y Bética, Salamanca 1965.

... 1985: "A propósito de algunas divinidades lusitanas", Symbolae Ludovico Mitxelena Septuagenario oblatae. Pars prior. Vitoria, 1985, 469-474.

BLAZQUEZ, J.M., 1962: Religiones primitivas de Hispania I: Fuentes literarias y epigráficas. Madrid, 1962.

CORNIDE, J., 1796: "Continuación de la memoria de D. Ignacio Hermosilla sobre las ruinas de Talavera la Vieja", Memorias de la Real Academia de la Historia 1, 1796, pp. 363-408.

CPILC: Hurtado de SAn Antonio, R. Corpus provincial de inscripciones latinas (Cáceres), Cáceres, 1977.

Curchin, L. A., 1985: “Vici and Pagi in Roman Spain”, Revue des Études Anciennes, 87, 1985, pp. $327-$ 343.

Fernandez OXeA, J. R., 1944-45: “Antigüedades cacereñas", Boletín del Seminario de Estudios de Arte y Arqueologia 11, 1944-1945, pp. 81-95.

... 1951: "De epigrafía cacereña", Boletín de la Real Academia de la Historia 128, 1951, pp. 165-196

GARCIA Y BELLIDO, A., 1956-1961: "Excavaciones en Augustobriga (Talavera la Vieja, Cáceres)”, Noticiario Arqueológico Hispánico 5, 1956-1961, pp. 235-237.

Gonzalez Cordero, A.; Cerrillo Martin de Caceres, F.J.; Alvarado Gonzalez, M. de; GutiérRez Morillo, A.; Suarez de Venegas Sanz, J., 1985: "Nuevas aportaciones a la epigrafía de Extremadura”, Studia Zamorensia VI. Histórica, 1985, 287-306.

HEp: Hispania Epigraphica. Ministerio de Cultura - Universidad Complutense de Madrid.

Hermosilla y Sandoval, I. de, 1796: "Noticias de las ruinas de Talavera la Vieja leídas en la Academia el 2 de julio de 1762", Memorias de la Real Academia de la Historia 1, 1796, pp. 345-362.

Kajanto, I., 1965: The Latin Cognomina. Helsinki-Helsingfors, 1965.

MelenA, J. L., 1985: “Jálama y la epigrafía latina del antiguo Corregimiento", Symbolae Ludovico Mitxelena Septuagenario oblatae. Pars prior. Vitoria, 1985, 475-530.

Palomar LaPeSA, M., 1957: La onomástica personal pre-latina de la antigua Lusitania. Estudio lingüístico, Salamanca, 1957.

REDONDO RodrigueZ, J. A., 1988: "Nuevos epígrafes romanos en Extremadura. Inscripciones de Trujillo, Salvatierra de Santiago, Conquista de la Sierra, Robledillo de Trujillo y Orellana”, Anuario de Estudios Filológicos 11, 1988, pp. 325-332.

Roso DE LunA, M., 1905: "Nuevas inscripciones romanas de la región norbense", Boletín de la Real Academia de la Historia 47, 1905, 60-71.

Tovar, A., 1989: Iberische Landeskunde, 3 Citerior Tarraconensis, Baden. Baden1989. 
Lam. I

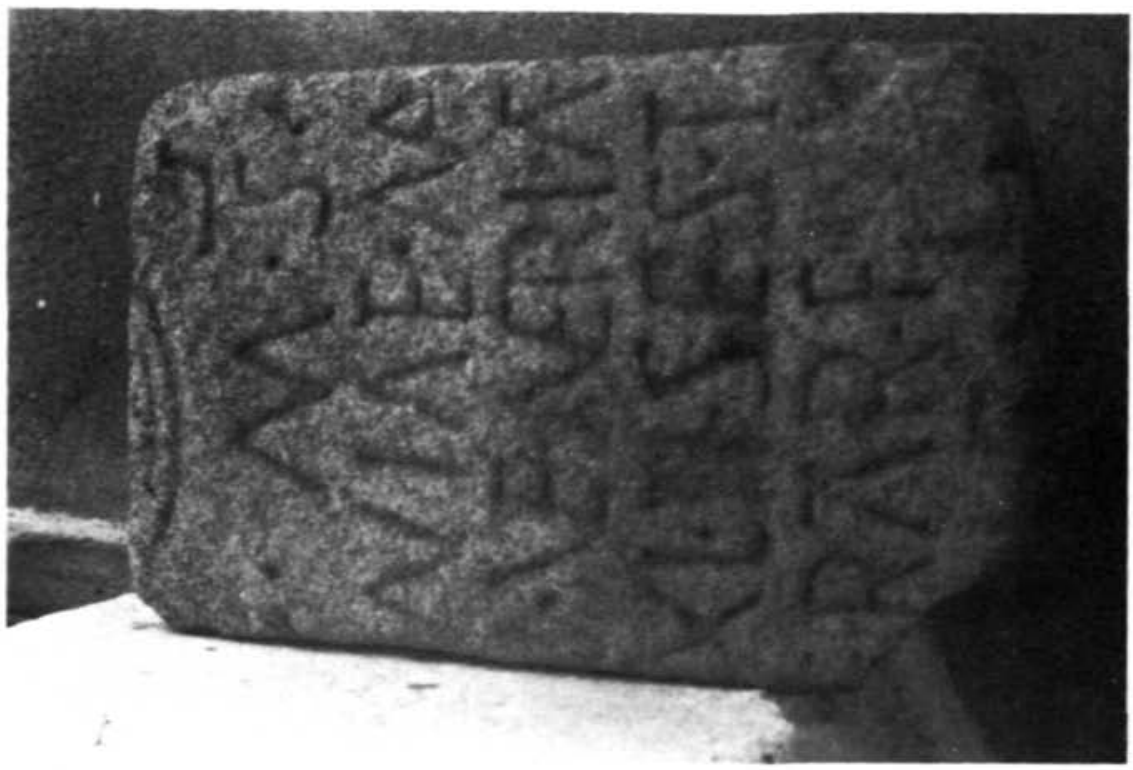

Figura 1: Herguijuela

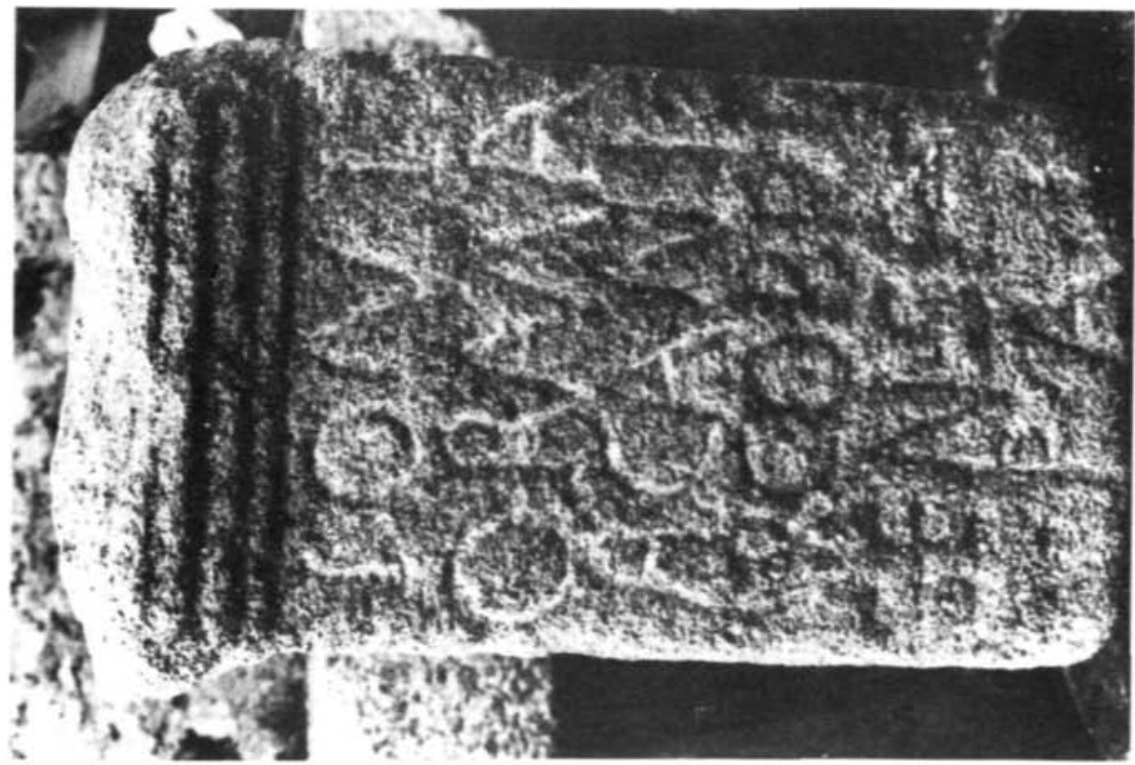

Figura 2: Perales del Puerto 
Lam. II

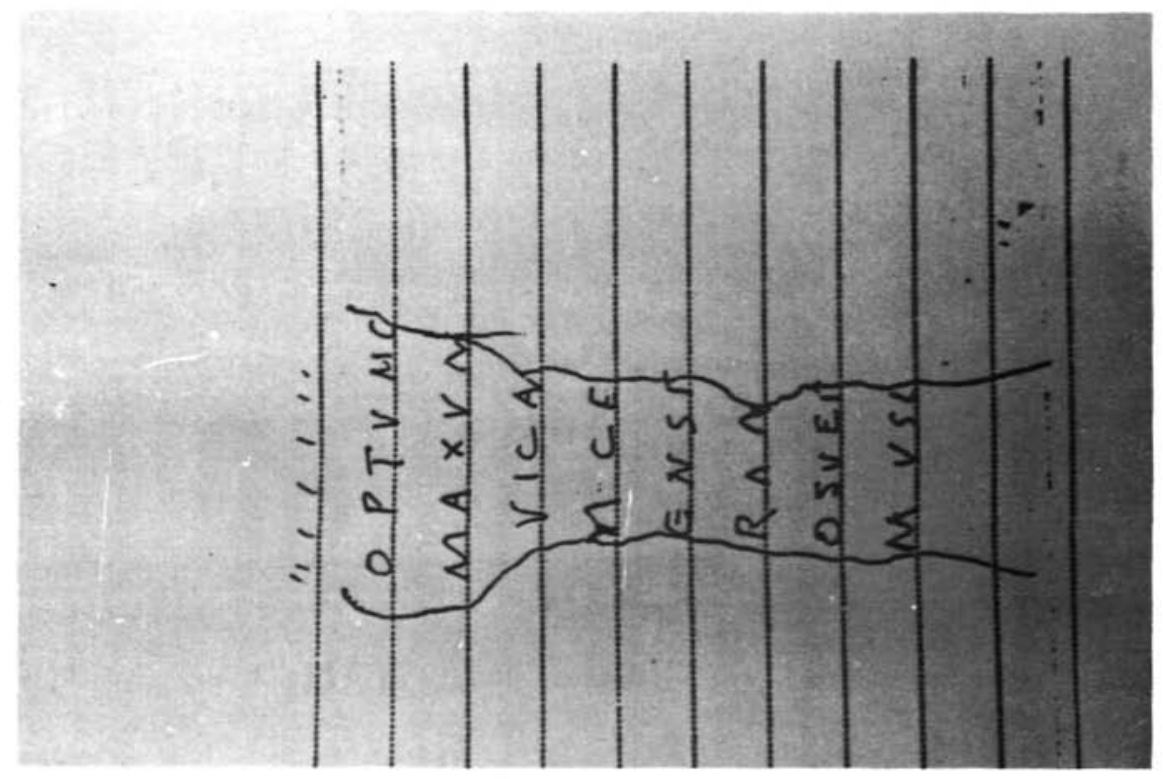

Figura 3: Perales del Puerto

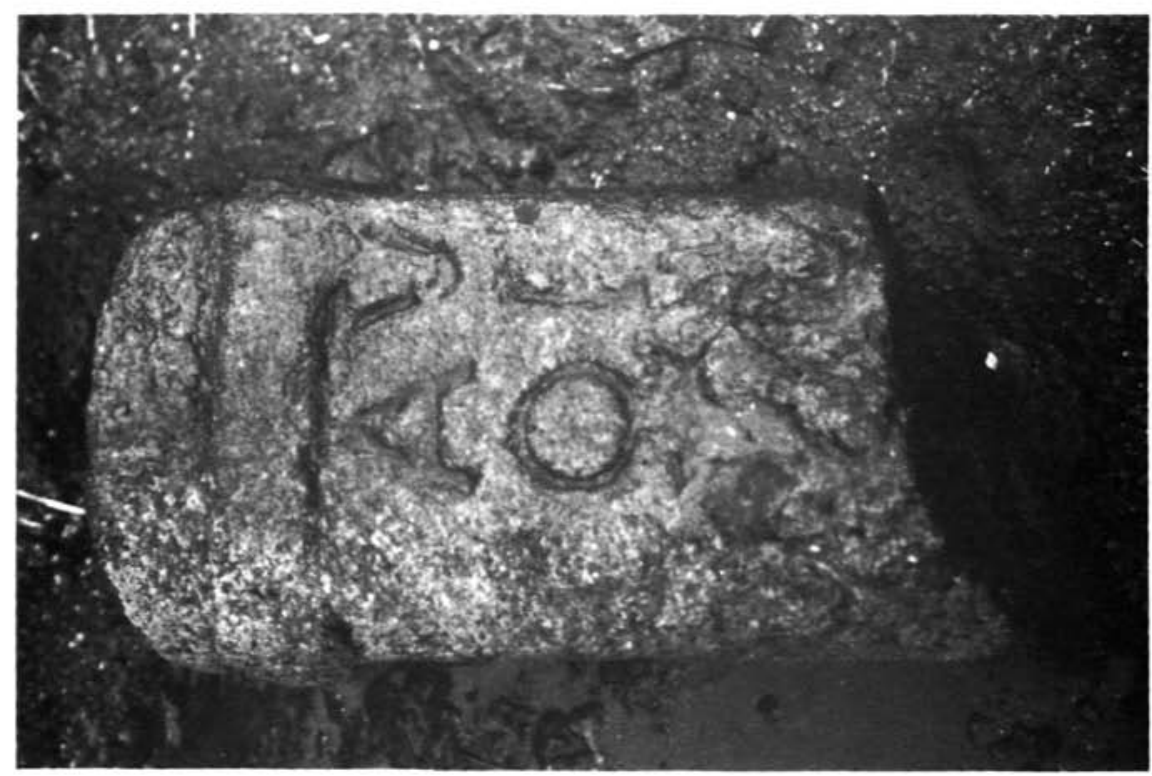

Figura 4: Plasenzuela 
Lam. III

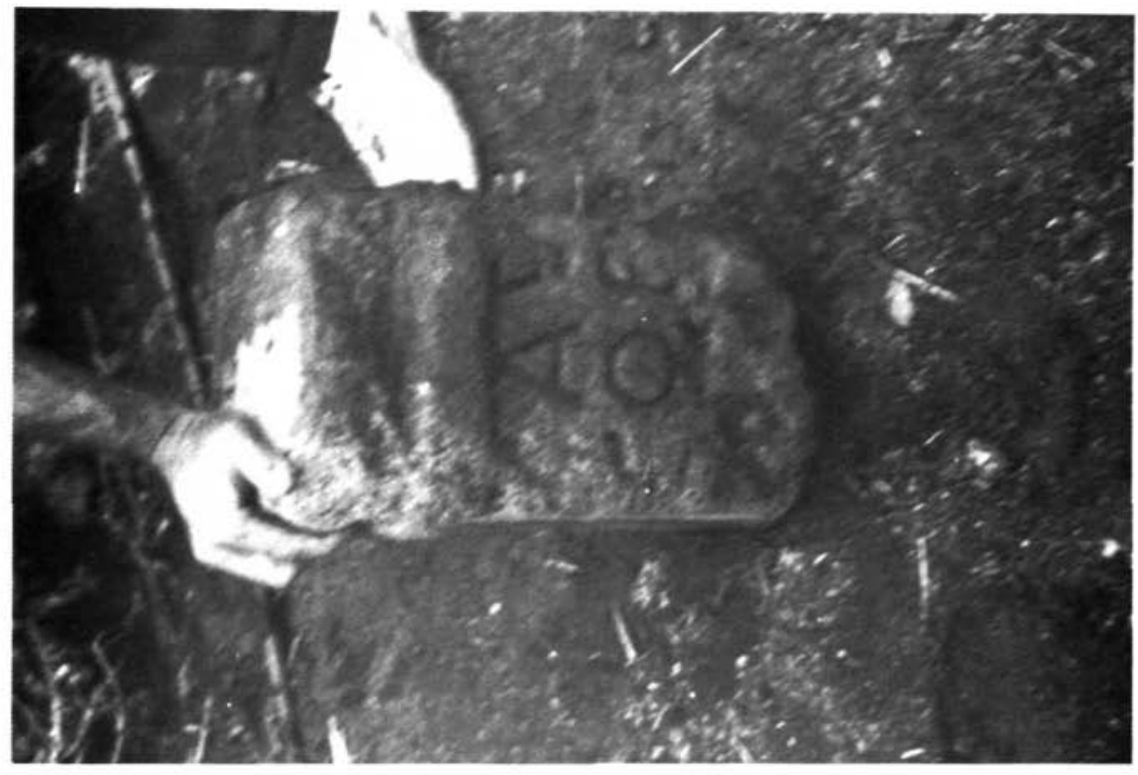

Figura 5: Plasenzuela

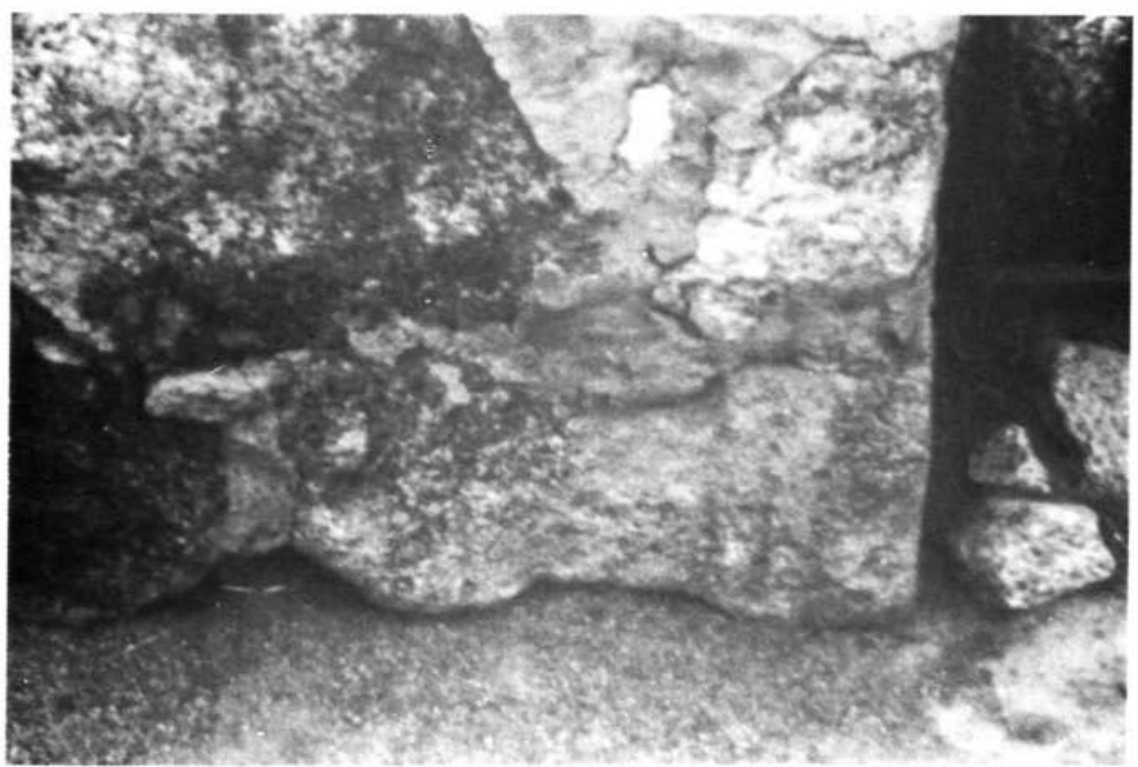

Figura 6: Plasenzuela 


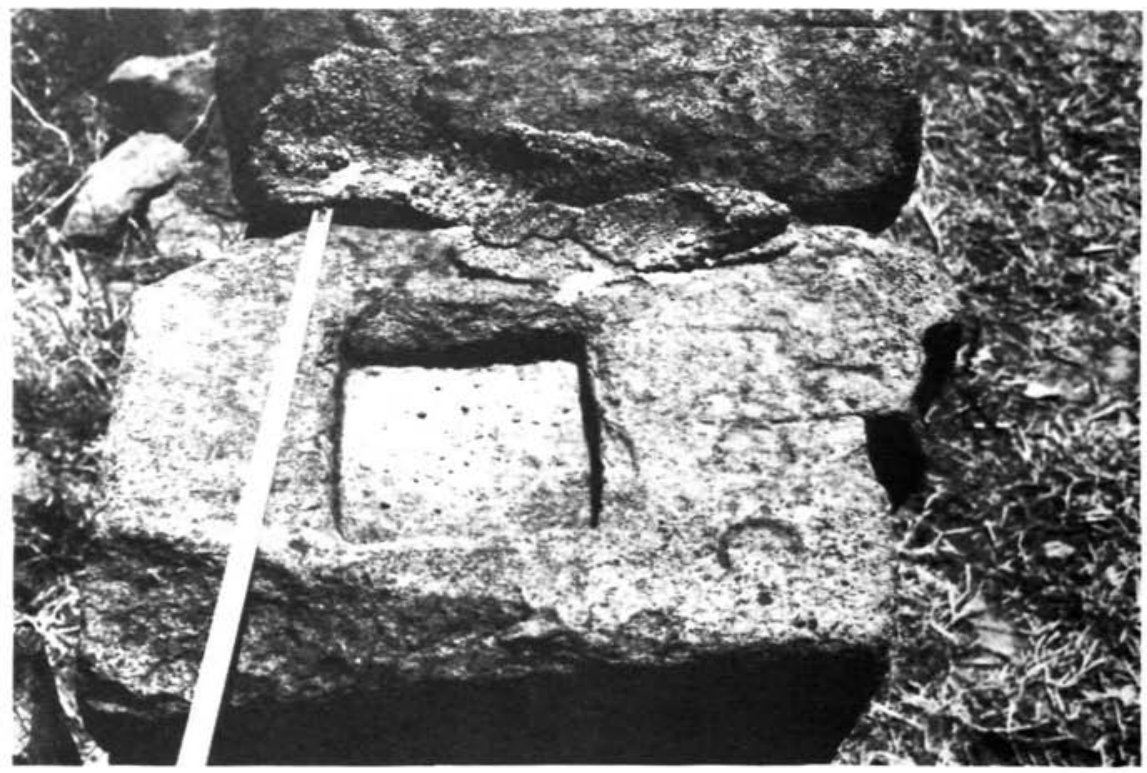

Figura 7: Robledillo de Trujillo

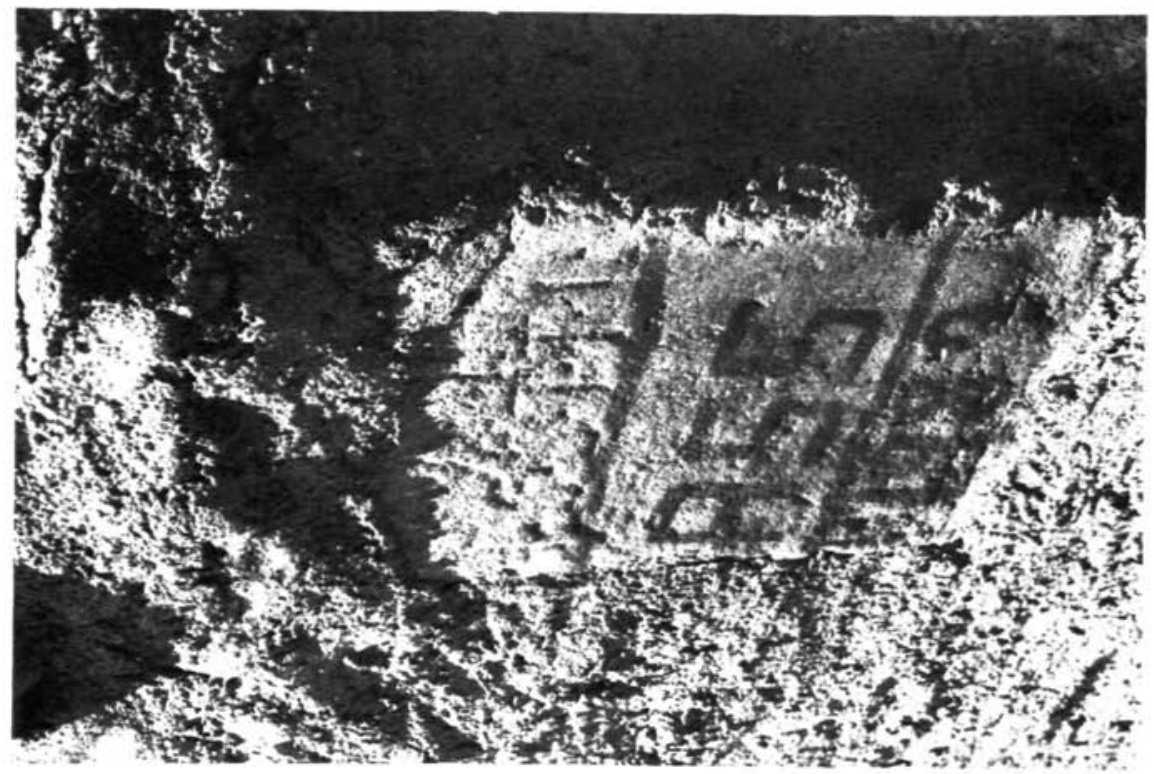

Figura 8: Robledillo de Trujillo 
Lam. V

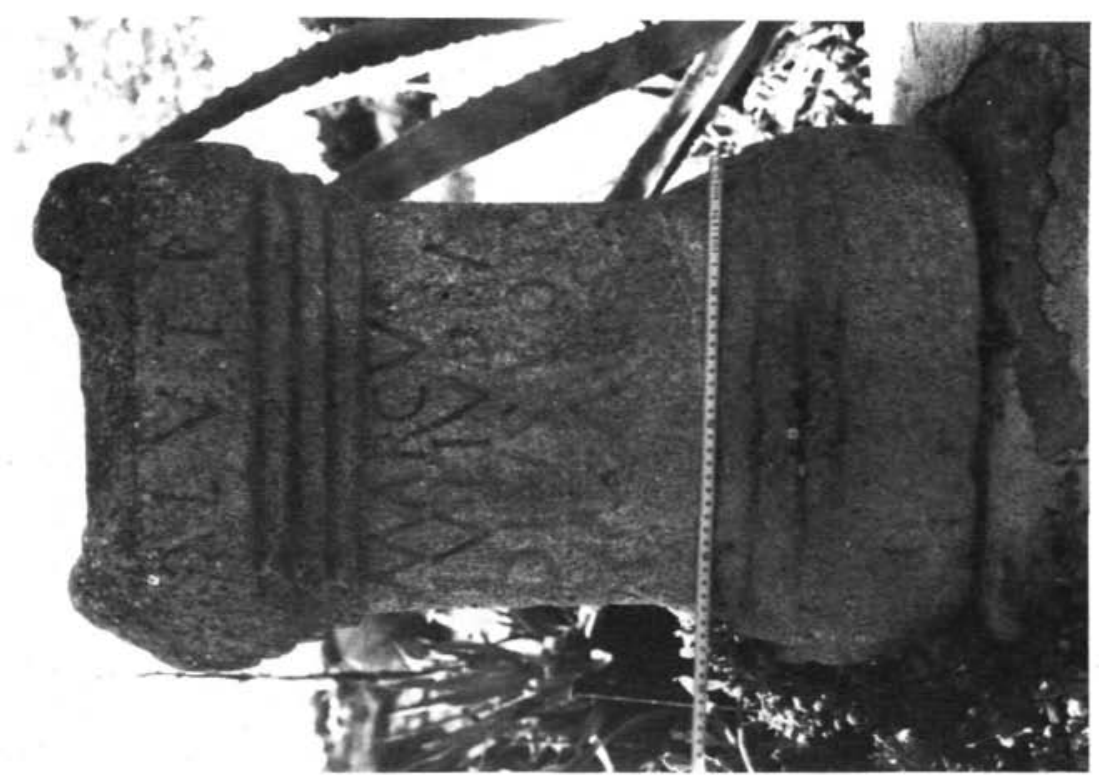

Figura 9: Robledillo de Trujillo
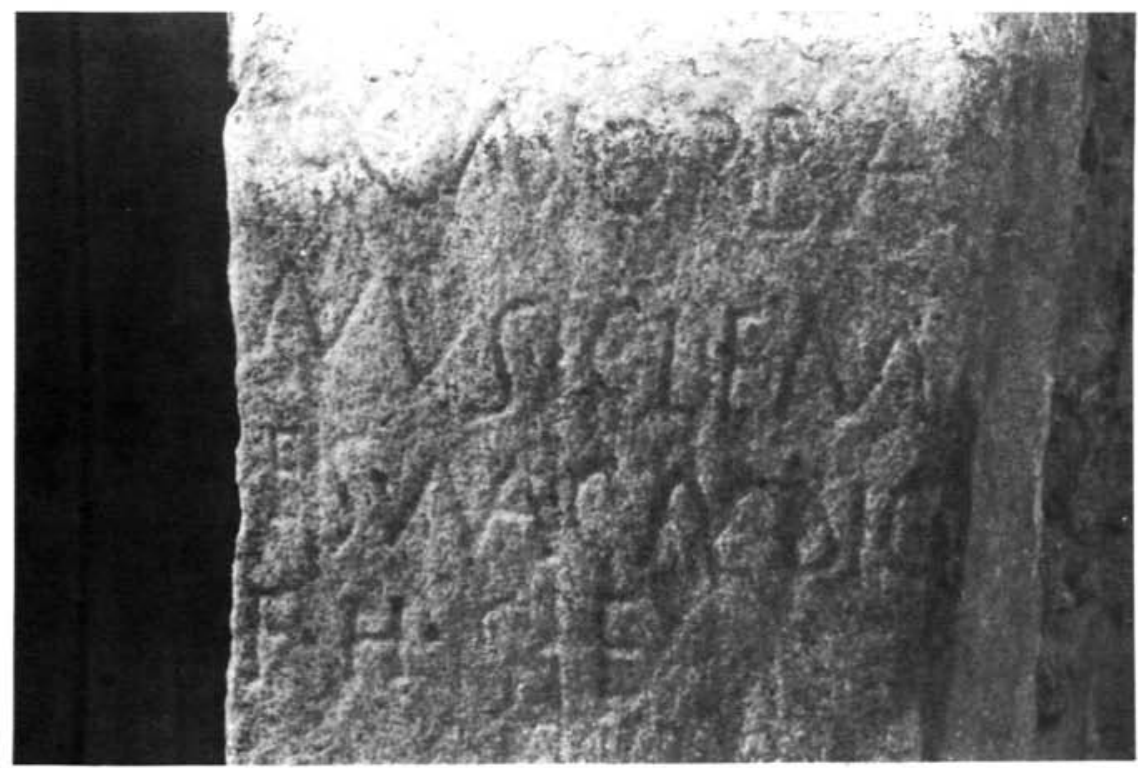

Figura 10: Salvatierra de Santiago 
Lam. VI

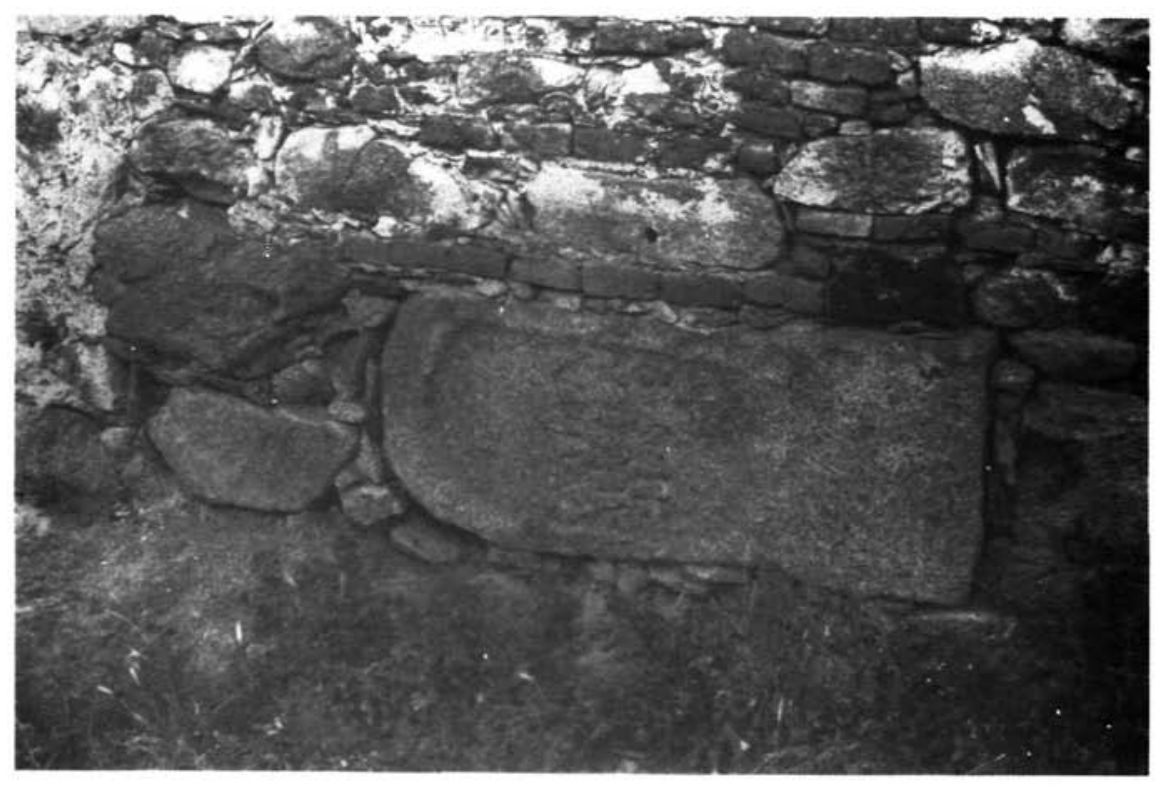

Figura 11: Salvatierra de Santiago

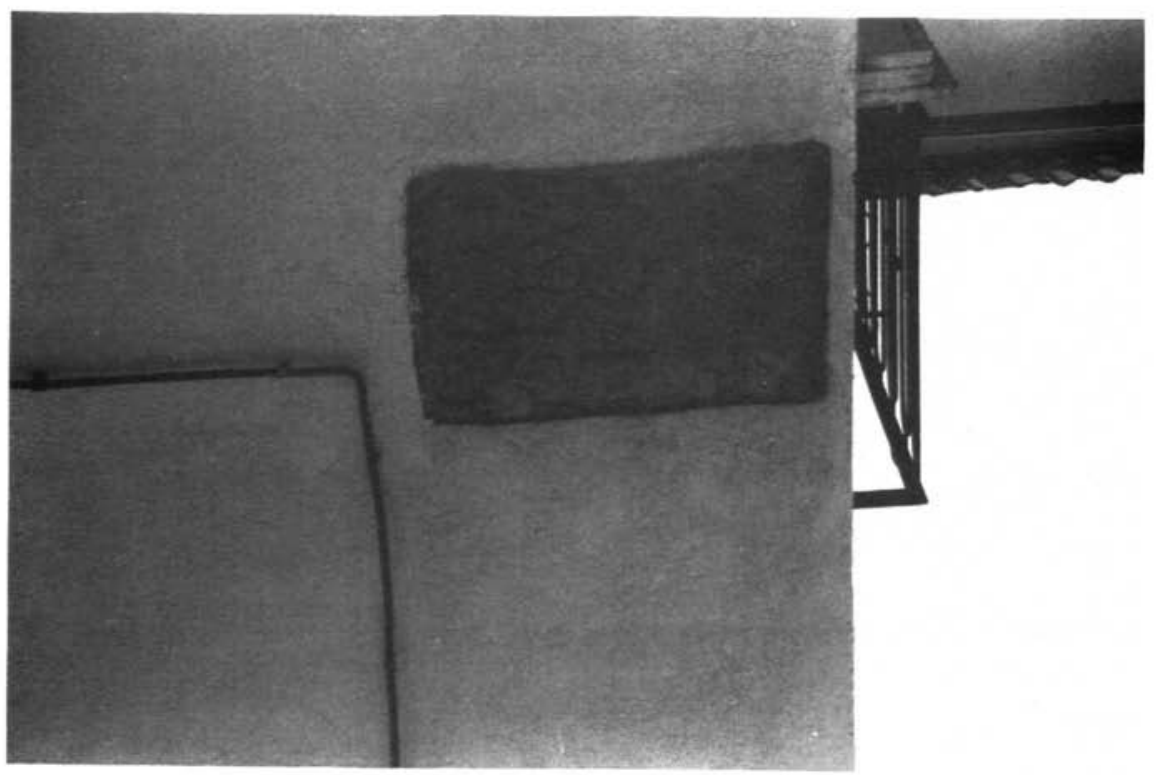

Figura 12: Ruanes 
Lam. VII

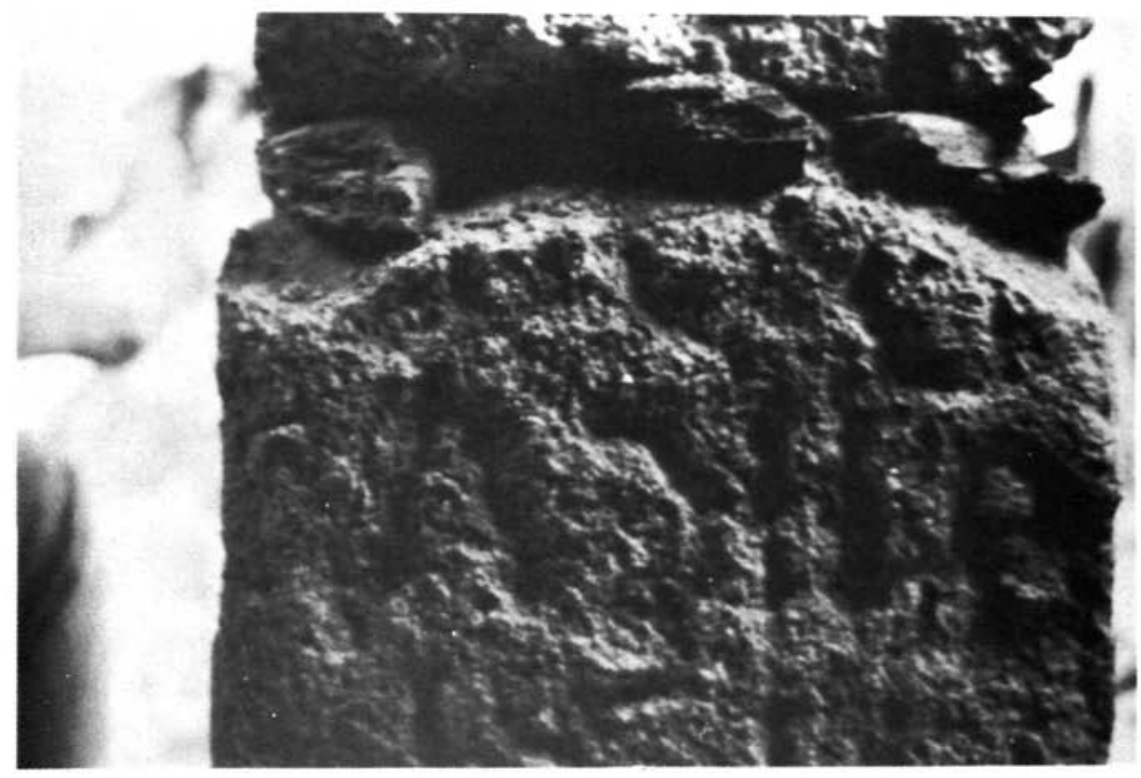

Figura 13: Ruanes

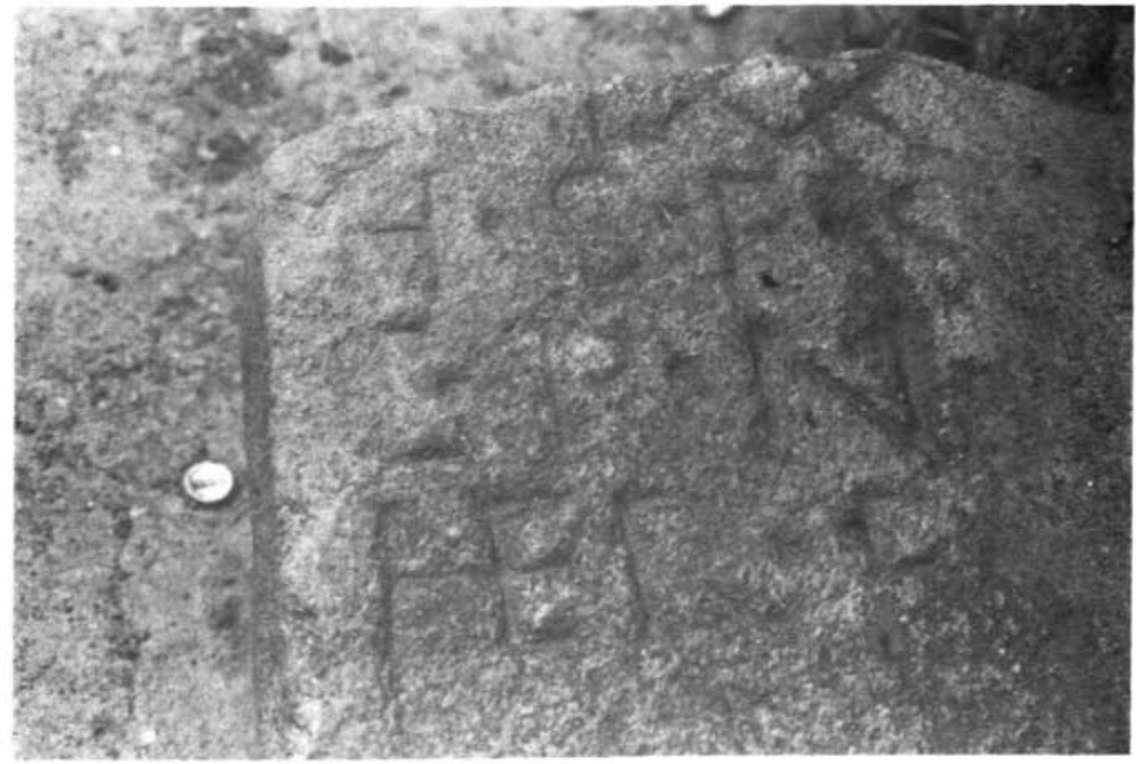

Figura 14: Santa Ana 
Lam. VIII

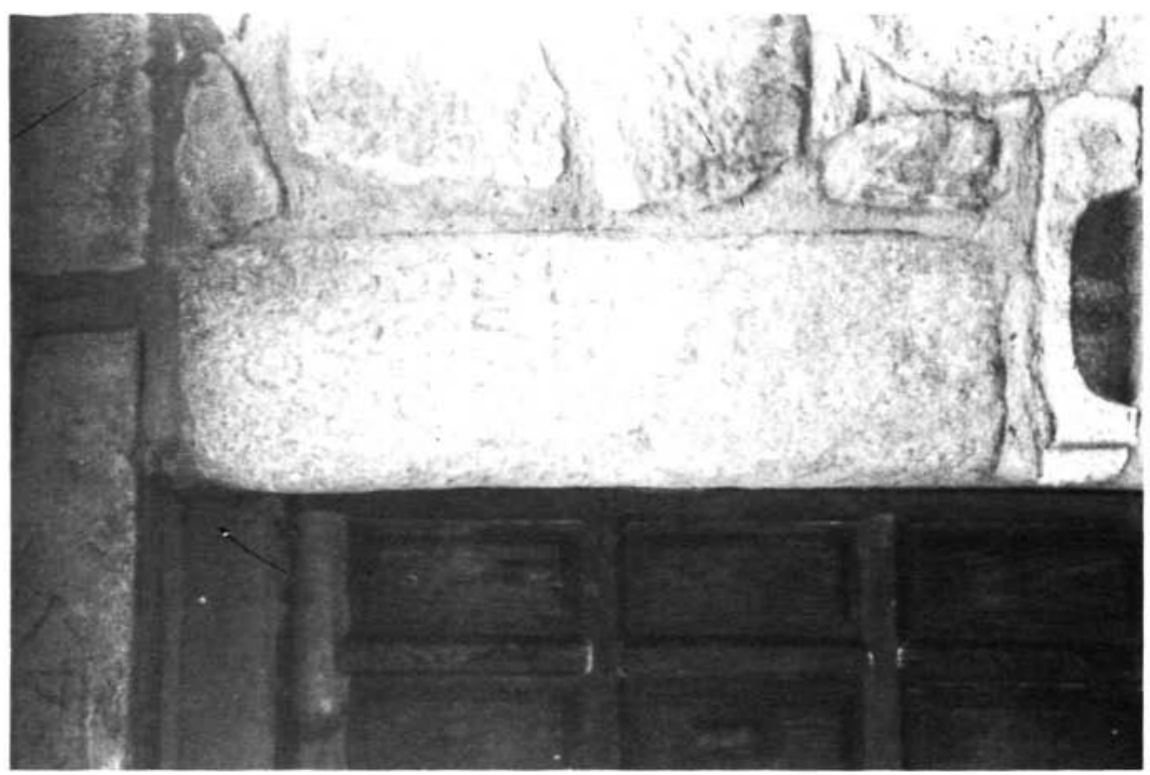

Figura 15: Santa Ana

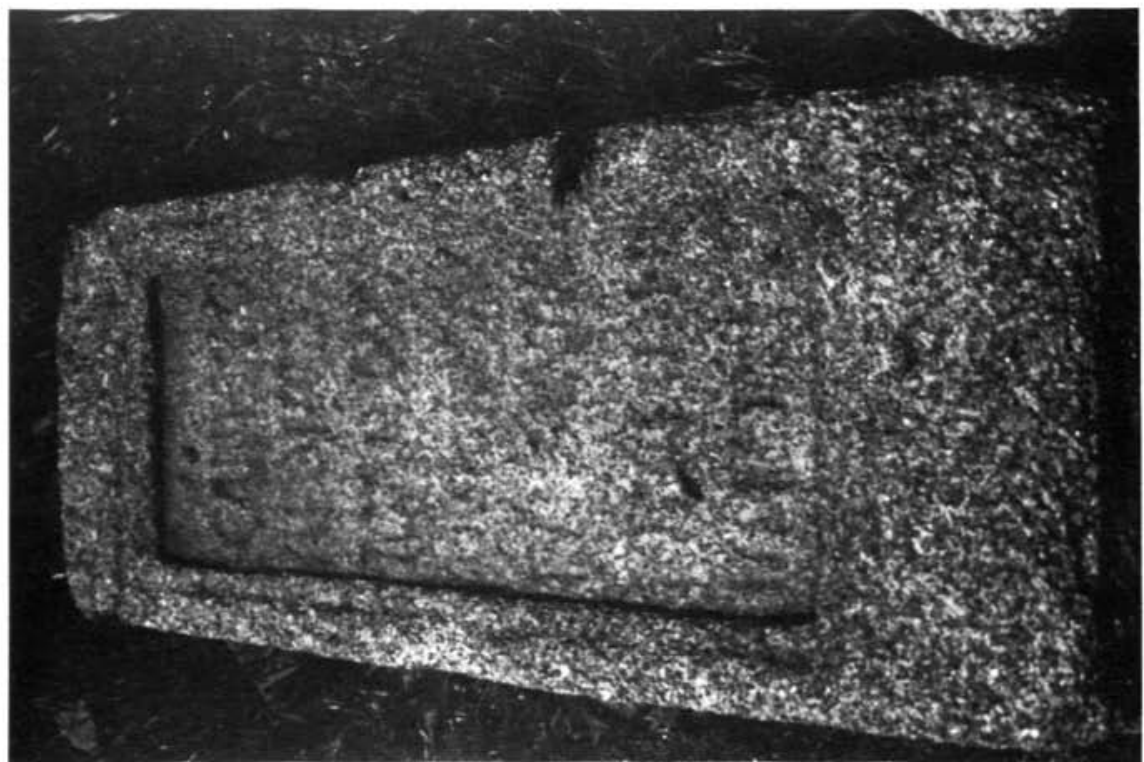

Figura 16: Talavera la Vieja 
Lam. IX

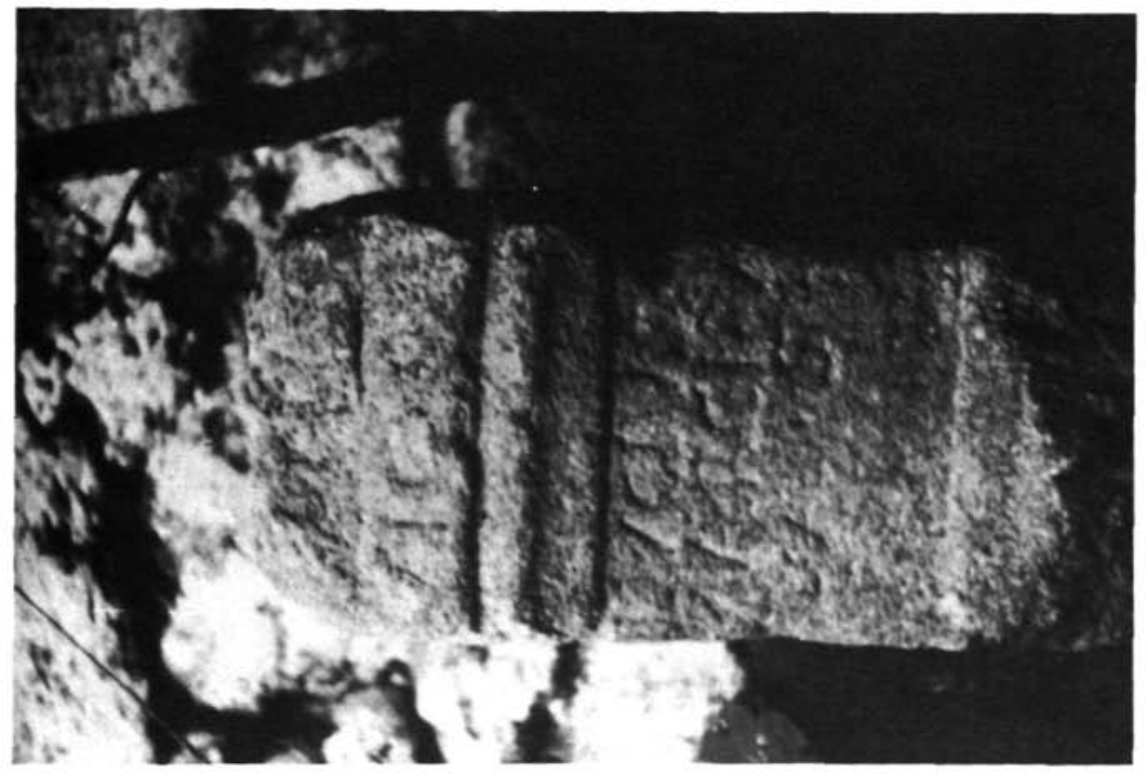

Figura 17: Talavera la vieja

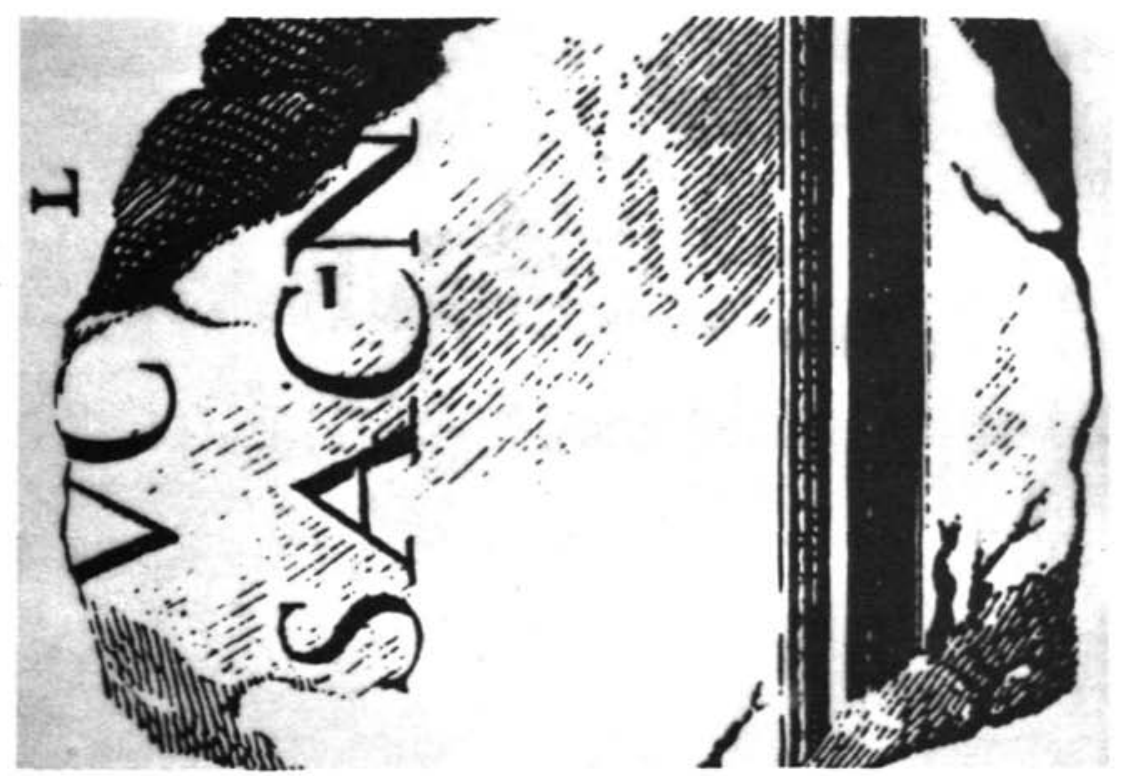

Figura 18: Talavera la Vieja 
Lam. X

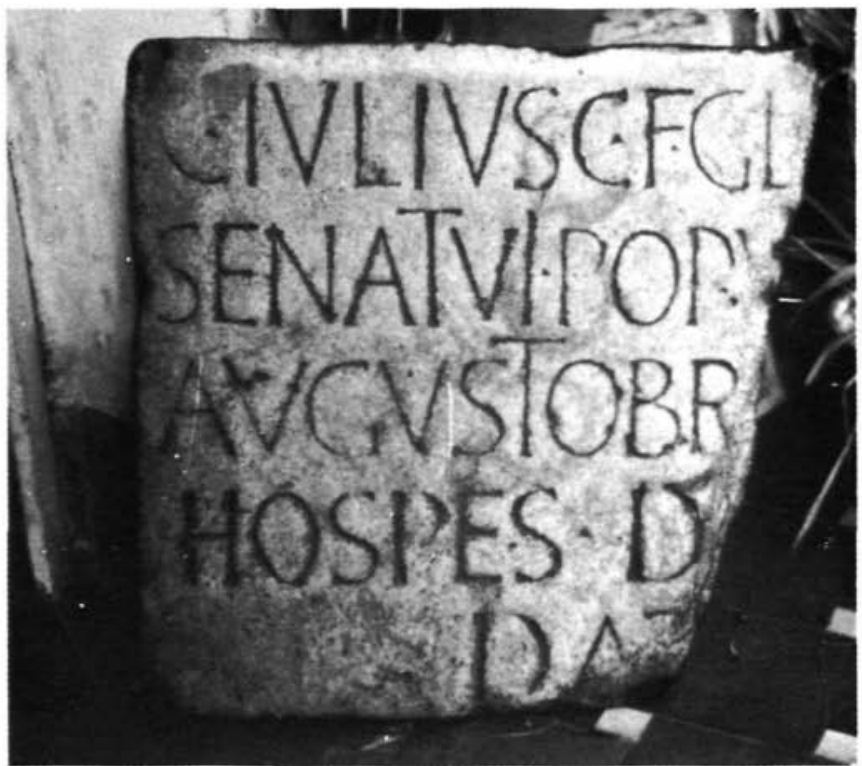

Figura 19: Talavera la Vieja

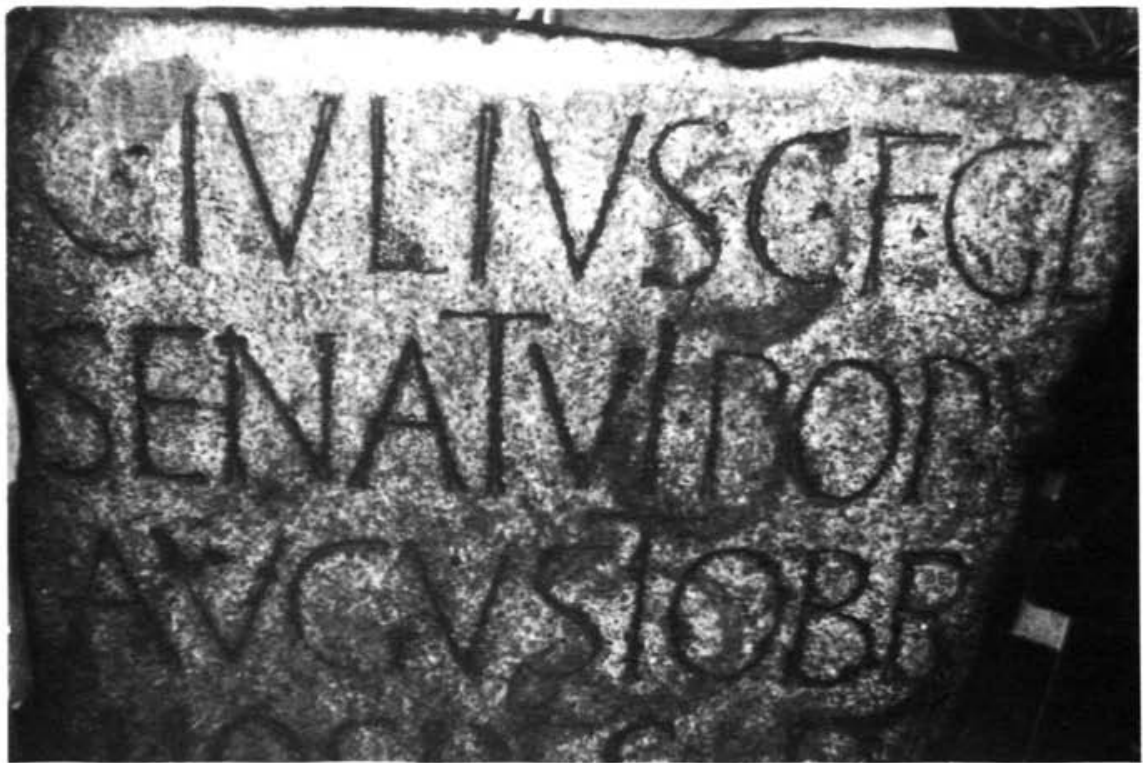

Figura 20: Talavera la Vieja 
Lam. XI

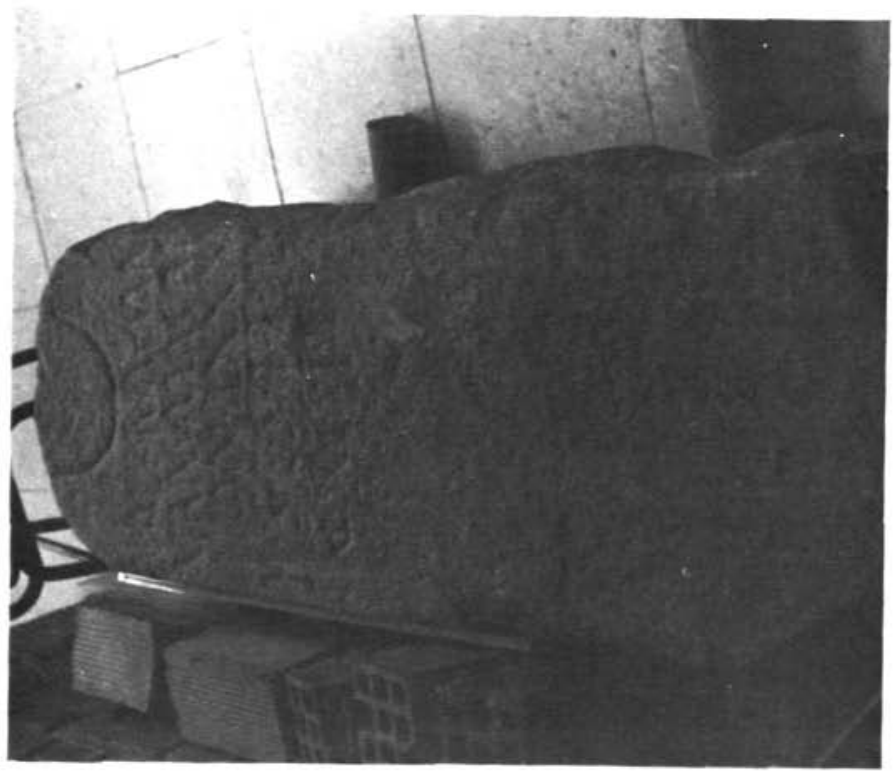

Figura 21: Magacela

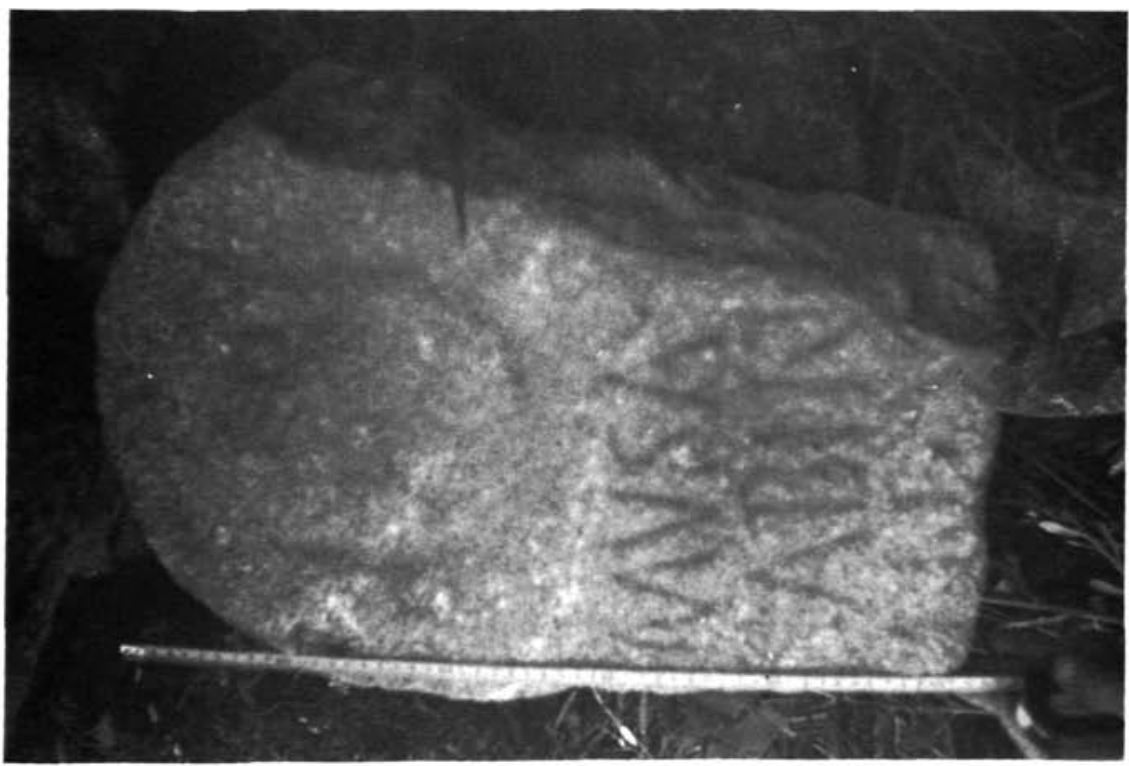

Figura 22: Magacela 